\title{
COMPATIBILIDADE E EFEITO DA MISTURA DE ISOLADOS DE RIZOBACTÉRIAS NA INDUÇÃO DO ENRAIZAMENTO E CRESCIMENTO DE CLONES DE EUCALIPTO ${ }^{1}$
}

\author{
Reginaldo Gonçalves Mafia ${ }^{2}$, Acelino Couto Alfenas ${ }^{2}$, Luiz Antônio Maffia ${ }^{2}$, Eraclides Maria Ferreira ${ }^{2}$ e \\ Leandro de Siqueira ${ }^{4}$
}

\begin{abstract}
RESUMO - Com vistas ao desenvolvimento de um produto biológico à base de rizobactérias promotoras do crescimento de plantas, este trabalho objetivou avaliar a compatibilidade e o efeito da mistura de isolados de rizobactérias pré-selecionados na indução do enraizamento e crescimento de clones de eucalipto. A compatibilidade entre os isolados de rizobactérias foi determinada por antibiograma nos meios de cultivo de Kado e Heskett e em meio B de King, enquanto o efeito da mistura de isolados foi avaliado por meio da aplicação dos isolados, individualmente ou em misturas, em substrato de enraizamento, empregando-se a mesma proporção de inóculo dos co-inoculantes. Em 64\% das possíveis combinações entre dois isolados, não se constataram reações de incompatibilidade. Os isolados VC2 e CIIb foram os mais compatíveis. De forma geral, não se observou sinergia entre misturas de isolados compatíveis, assim como também não ocorreu, geralmente, redução na eficiência da mistura de isolados incompatíveis.
\end{abstract}

Palavras-chave: Eucalyptus, PGPR, biológico e sinergia.

\section{COMPATIBILITY AMONG RHIZOBACTERIA ISOLATES AND EFFECT OF MIXTURE OF ISOLATES IN INDUCING ROOTING AND GROWTH OF EUCALYPTUS CLONES}

\begin{abstract}
Isolates of rhizobacteria that induced both rooting and growth of eucalyptus clones were previously selected. To assist developing a biological product based on those isolates, the compatibility among them and the effect of mixture of isolates were evaluated. The compatibility among rhizobacteria isolates was assessed by antibiograms in both Kado \& Heskett and King B culture media, whereas the effect of isolate mixtures was evaluated by applying the isolates, either alone or mixed but always in the same proportions, in rooting substrate. No antagonism between isolates was observed in $64 \%$ of the possible combinations of two isolates. Isolates VC2 and CIIb were the most compatible. In general, it was observed no synergistic interaction in mixture of compatible isolates, as well as no efficiency reduction in mixture of incompatible isolates.
\end{abstract}

Keywords: Eucalyptus, PGPR, biological, and synergy.

\section{INTRODUÇÃO}

No Brasil, as constantes expansões do setor florestal têm impulsionado o desenvolvimento de novas tecnologias de produção. Recentemente, foi demonstrado o efeito benéfico da aplicação de rizobactérias promotoras do crescimento de plantas (KLOEPPER e SCHROTH,
1978) sobre o enraizamento, crescimento e controle biológico de doenças do eucalipto (TEIXEIRA, 2001; ALFENAS et al., 2004; MAFIA et al., 2005). Os mecanismos envolvidos na promoção de crescimento induzido por rizobactérias promotoras de crescimento não são totalmente conhecidos. No entanto, incluem

\footnotetext{
${ }^{1}$ Recebido em 04.07.2006 e aceito para publicação em 29.03.2007

${ }^{2}$ Departamento de Fitopatologia da Universidade Federal de VIçosa(UFV). Viçosa, MG 36570-000. E-mail:<rgoncalves@ aracruz.com.br>; <aalfenas@ufv.br>; <lamaffia@ufv.br>e<ferreiraem@yahoo.com.br>.

${ }^{3}$ Suzano Papel e Celulose. Itapetininga-SP 18200-000. E-mail: <lsiqueira@ suzano.com.br>.
} 
a habilidade de produzir ou mudar a concentração de fitormônios como ácido indolacético, ácido giberélico, citocininas e etileno, fixação assimbiótica de $\mathrm{N}_{2}$ e antagonismo contra microrganismos fitopatogênicos, seja por produção de sideróforos, b-1,3 glucanase, quitinases, antibióticos e cianeto ou solubilização de fosfato mineral e outros nutrientes (CATTELAN et al., 1999). Ademais, algumas rizobactérias podem promover o crescimento indiretamente por afetar a fixação simbiótica de $\mathrm{N}_{2}$, nodulação ou ocupação por nódulos (POLONENKO et al., 1987).

O uso de rizobactérias para aumentar a produtividade de plantas tem sido extensivamente estudado há vários anos e para diversas culturas agronômicas, como: batata (BURR et al., 1978; KLOEPPER et al., 1980), cana-de-açúcar (SUSLOW e SCHROTH, 1982), canola (KLOEPPER et al., 1988), amendoim (TURNER e BACKMAN, 1991), trigo (WELLER e COOK, 1986), cevada (ISWANDI et al., 1987), milho (LALANDE et al., 1989), tomate (GAGNÉ et al., 1993), entre outras. Para espécies arbóreas, as recentes investigações têm evidenciado resultados promissores (CHANWAY e HOLL, 1993ab, 1994; CHANWAY, 1997; ENEBACK et al., 1998; SHISHIDO e CHANWAY, 2000). No entanto, há necessidade de estudos que visem otimizar o processo de rizobacterização.

Existem na literatura vários exemplos de estudos de biocontrole, tendo sido avaliado o efeito sinérgico da mistura de fungos antagonistas (DATNOFF et al., 1993; BUDGE et al., 1995; DATNOFF et al., 1995), mistura de fungo e bactérias (DUFFY e WELLER, 1995; DUFFY et al., 1996; JANISIEWICZ, 1996; LEEMAN et al., 1996) e mistura de bactérias (JONHSON et al., 1993; PIERSON e WELLER, 1994; RAAIJMAKERS et al., 1995; STOCKWELL et al., 1996; SCHISLER et al., 1997; RAUPACHe KLOEPPER, 1998; BOER etal., 1999). Embora na maioria dos casos a mistura promova maior controle, em comparação com a aplicação dos agentes de controle biológico separadamente, existem relatos de redução da eficiência. Assim, como pré-requisito tem sido aconselhado considerar a compatibilidade entre os coinoculantes (RAUPACH e KLOEPPER, 1998). Desse modo, este trabalho objetivou avaliar a compatibilidade e o efeito da mistura de isolados de rizobactérias préselecionados na indução do enraizamento e crescimento de clones de eucalipto.

R. Árvore, Viçosa-MG, v.31, n.4, p.635-643, 2007

\section{MATERIAL E MÉTODOS}

\subsection{Isolados de rizobactérias e preparo do inóculo}

Empregaram-se oito isolados de rizobactérias (FL2 - Pseudomonas aeruginosa (Schroeter) Migula; S1, S2 e 3918 - Bacillus subtilis Cohn; MF2 - Pseudomonas sp. Migula; CIIb - Stenotrophomonas maltophilia (Hugh) Palleroni \& Bradbury; Ca - Pseudomonas fulva Lizuga \& Komagata; e VC2 - Isolado não identificado), obtidos a partir da rizosfera de mudas clonais de eucalipto de diferentes regiões do país. Esses microrganismos foram pré-selecionados de acordo com a capacidade de promover incremento na biomassa de raízes e induzir o enraizamento adventício (TEIXEIRA, 2001).

Para se proceder ao preparo do inóculo, cada isolado foi cultivado separadamente em meio solidificado de Kado e Heskett (1970), no escuro. Após 48 h, procedeu-se à raspagem das colônias de bactérias em solução salina ( $\mathrm{NaCl} 0,85 \%)$. A concentração de cada suspensão foi ajustada de acordo com a correlação entre a densidade ótica e o número de unidades formadoras de colônias (u.f.c./mL) para 0,2 Abs. (540 $\mathrm{nm}$ ), o que corresponde aproximadamente a $10^{8}$ u.f.c./ $\mathrm{mL}$. As suspensões de inóculo foram mantidas sob refrigeração até sua utilização.

\subsection{Compatibilidade entre isolados de rizobactérias}

Visando avaliar a compatibilidade entre os isolados de rizobactérias, foi realizado o pareamento das culturas em meio de Kado e Heskett (1970) e em meio B de King (KING et al., 1954) pela metodologia do antibiograma. Para isso, discos ( $5 \mathrm{~mm}$ de diâmetro) de papel-filtro $\left(n^{\circ} 1\right)$ foram previamente embebidos na suspensão de rizobactérias e secados sob ventilação forçada por 15 min. Após essa etapa, esses discos foram depositados sobre a cultura do isolado de rizobactéria confrontante com 24 h de idade (incubação a $27^{\circ} \mathrm{C}$, no escuro), desenvolvida em meio sólido em placas de Petri. Após a incubação a $27^{\circ} \mathrm{C}$ por $24 \mathrm{~h}$, no escuro, realizou-se a avaliação da presença ou ausência de halos de inibição. Todas as combinações foram realizadas de forma que cada isolado foi pareado com todos os demais presentes na placa de Petri ou no disco de papel-filtro. Além disso, amostras de discos embebidos com os isolados foram depositadas sob meio de Kado \& Heskett e incubados, nas mesmas condições, para certificação da viabilidade das culturas e da inexistência de contaminantes fúngicos e, ou, bacterianos. 
$\mathrm{Na}$ avaliação da compatibilidade entre os isolados de rizobactérias, empregaram-se cinco repetições em cada combinação, cada uma constituída de uma placa com cinco discos. As avaliações foram realizadas de forma qualitativa, atribuindo sinais positivos e negativos nos casos em que ocorria compatibilidade ou incompatibilidade, respectivamente.

\subsection{Efeito da mistura de isolados de rizobactérias}

De posse dos resultados sobre compatibilidade entre os isolados de rizobactérias, foram instalados experimentos, independentes, para cinco clones (1270, 3016, C041, P4295 e VR3709) de eucalipto, nos quais se testaram quatro isolados (FL2, MF2, S2 e CIIb) de rizobactérias, visando avaliar o possível efeito sinérgico entre os isolados sabidamente compatíveis. No primeiro ensaio, testaram-se os isolados FL2, MF2 e S2, individualmente ou nas misturas M1 (FL2 + MF2), M2 $(\mathrm{FL} 2+\mathrm{S} 2)$ e M3 (MF2 + S2) no clone 1270. No segundo, testaram-se os mesmos tratamentos no clone 3016. Nos clones C041, P4295 e VR3709, testaram-se os isolados FL2, CIIb e S2 e as misturas M1 (FL2 + CIIb), M2 (FL2 $+\mathrm{S} 2)$ e M3 (CIIB + S2). Em todos os experimentos, as suspensões de inóculo de rizobactérias foram adicionadas ao substrato de enraizamento na proporção de $0,1 \mathrm{~mL} / \mathrm{cc}$ de substrato e homogeneizadas em misturador apropriado. Empregou-se a mesma proporção (1:1) de inóculo para realização da mistura de isolados. Após a microbiolização do substrato, miniestacas dos diferentes clones foram coletadas de minijardins clonais de eucalipto e postas para enraizar no substrato. Após 25 dias de permanência em casa de enraizamento, realizouse a avaliação do índice de enraizamento e da biomassa radicular. No primeiro caso, quantificou-se o número de miniestacas enraizadas em relação ao total. A avaliação da biomassa radicular foi realizada após a remoção dos resíduos de substrato e secagem das raízes em estufa por $24 \mathrm{~h}$ a $70^{\circ} \mathrm{C}$.

\subsection{Análises estatísticas}

Os dados de cada ensaio sobre mistura de isolados foram submetidos à análise de variância (ANOVA), aplicando-se o teste $\mathrm{F}$ a $5 \%$ de probabilidade. Posteriormente, as médias foram comparadas pelo teste de Tukey. Quando necessário, os dados de enraizamento (E) foram transformados por arco-seno (E/100) ou por $\log (1 / 1$ - (E/100)) (BARTLETT, 1947) e os de biomassa seca de raízes (BR) por raiz quadrada. As análises estatísticas foram realizadas com o auxílio do programa SAEG (EUCLYDES, 1983).

\section{RESULTADOS}

$\mathrm{Na}$ avaliação da compatibilidade entre os isolados de rizobactérias, observou-se a mesma resposta nos pareamentos em meio de cultivo de Kado \& Heskett e em meio B de King. Além disso, não se contataram diferenças quanto à compatibilidade para uma mesma mistura, em relação à presença de um mesmo isolado na placa de Petri ou no disco de papel-filtro. Em 64\% das combinações possíveis entre dois isolados, não foram constatadas reações de incompatibilidade. Os isolados VC2 e CIIb foram os mais compatíveis, totalizando cada um $90 \%$ de misturas possíveis. Em contrapartida, o isolado $\mathrm{S} 1$ demonstrou menores possibilidades de combinação. Nas misturas entre isolados da mesma espécie, como aqueles pertencentes à espécie $B$. subtilis, observaram-se $70 \%$ de compatibilidade (Quadro 1 e Figura 1).

Quadro 1 - Compatibilidade entre isolados de rizobactérias em meio de cultivo Table 1 -Compatibility among rhizobacteria isolates in culture medium

\begin{tabular}{|c|c|c|c|c|c|c|c|c|c|c|}
\hline \multicolumn{11}{|c|}{ Isolados de rizobactérias } \\
\hline & $\mathrm{S} 2$ & 3918 & $\mathrm{VC} 2$ & R1 & MF4 & $\mathrm{S} 1$ & CIIb & FL2 & $\mathrm{Ca}$ & MF2 \\
\hline $\mathrm{S} 2$ & $+*$ & - & + & + & - & - & + & - & - & - \\
\hline 3918 & - & + & + & + & - & + & + & - & - & - \\
\hline VC2 & + & + & + & - & + & + & + & + & + & + \\
\hline R1 & + & + & - & + & + & - & + & - & + & + \\
\hline MF4 & - & - & + & + & + & - & + & + & + & + \\
\hline $\mathrm{S} 1$ & - & + & + & - & - & + & - & - & - & - \\
\hline CIIb & + & + & + & + & + & - & + & + & + & + \\
\hline FL2 & - & - & + & - & + & - & + & + & + & + \\
\hline $\mathrm{Ca}$ & - & - & + & + & + & - & + & + & + & + \\
\hline MF2 & - & - & + & + & + & - & + & + & + & + \\
\hline
\end{tabular}

* Sinais positivos (+) e negativos (-) indicam combinações compatíveis e incompatíveis, respectivamente. 


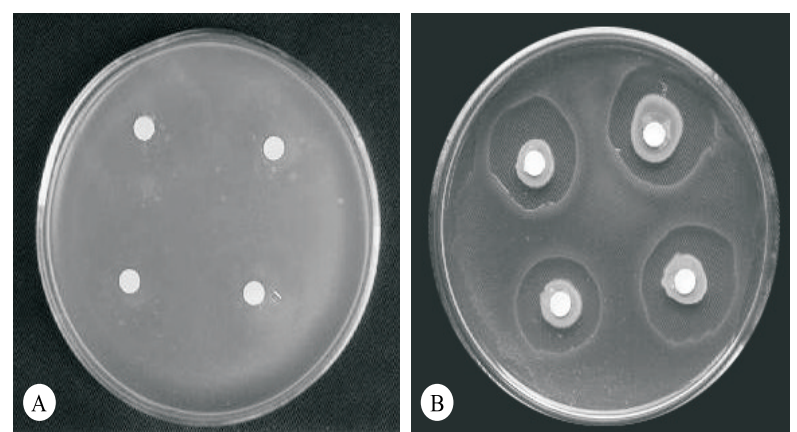

Figura 1-Compatibilidade (A) e incompatibilidade (B) entre isolados de rizobactérias avaliadas por pareamento de culturas.

Figure 1 - Compatibility (A) or incompatibility (B) among rhizobacteria isolates assessed by cultures pairing.

Nos ensaios de mistura de isolados, os incrementos variaram de acordo com o isolado de rizobactéria, aplicado isoladamente ou em mistura, e de acordo com o clone de eucalipto. Assim, constatou-se no clone 1270 incremento para enraizamento médio, independentemente da aplicação dos isolados, individualmente ou nas misturas, mesmo nas misturas M2 (FL2 + S2) e M3 (MF2

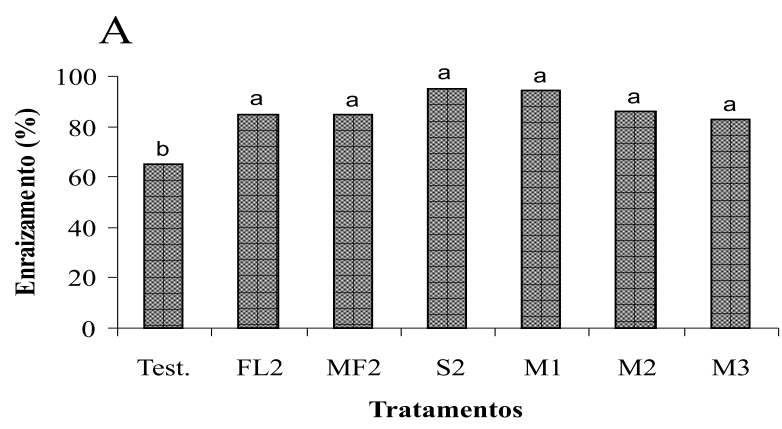

B

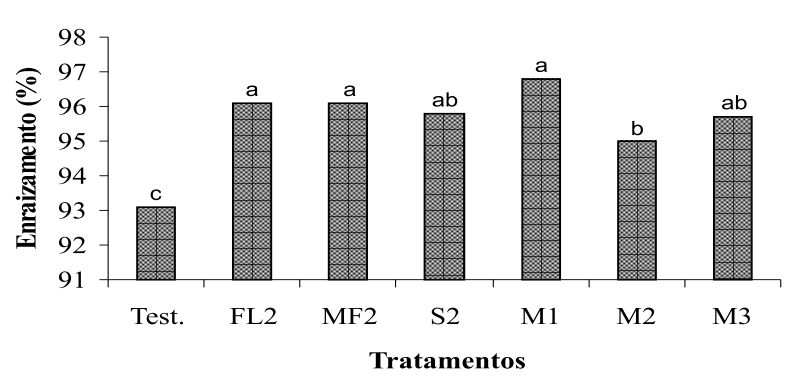

+ S2), previamente caracterizada como incompatível. Para biomassa radicular, observou-se que o isolado S2 e a mistura M1 (FL2 + MF2), sabidamente compatível, foram os melhores tratamentos, com incrementos, em termos porcentuais, de 62 e $57 \%$, respectivamente. Na mistura M2 (FL2 + S2), considerada compatível, também houve incremento com relação a essa variável (Figura 2A).

No clone 3016, considerando as duas variáveis avaliadas, todos os tratamentos diferiram da testemunha. Como ocorrido no clone 1270, a mistura M1 (FL2 + MF2) destacou-se como a mais promissora para enraizamento, diferindo da mistura M2 (FL2 + S2), sabidamente incompatível. Porém não houve diferença da mistura $\mathrm{M} 1$ em relação ao tratamento com os isolados FL2, MF2 e S2 e da mistura M3 (MF2 + S2). Para biomassa radicular não ocorreu diferenciação entre os tratamentos de rizobactérias, independentemente de estarem ou não combinados com outros isolados. O maior incremento foi observado no isolado MF2, com $64 \%$ de ganho, em termos porcentuais, e em relação à testemunha (Figura 2B).
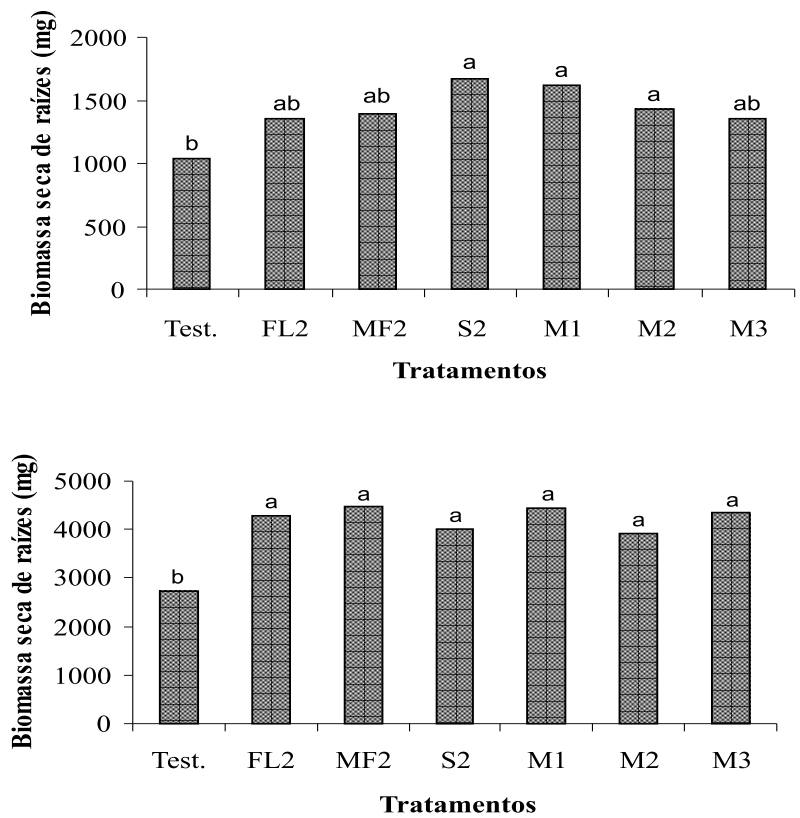

Figura 2 - Enraizamento e biomassa radicular dos clones 1270 (A) e 3016 (B) propagados em substrato microbiolizado com os isolados FL2, MF2 e S2 e com as misturas M1 (FL2 + MF2), M2 (FL2 + S2) e M3 (MF2 + S2). Colunas sob a mesma letra não diferem entre si, estatisticamente, pelo teste de Tukey $(\mathrm{P}<0,05)$.

Figure 2 -Rooting (\%) and root biomass $(\%)$ of clones $1270(A)$ and $3016(B)$ propagated in substrate that was microbiolized with isolates FL2, MF2, S2, or the mixtures M1 (FL2 + MF2), M2 (FL2 + S2) or M3 $(M F 2+S 2)$. Bars with the same letters are not statistically different by the Tukey Test $(P=0,05)$.

R. Árvore, Viçosa-MG, v.31, n.4, p.635-643, 2007 
A propagação do clone C041 em substrato microbiolizado propiciou distinção entre os tratamentos para enraizamento quanto à mistura M3 (CIIb + S2). Nesse caso, a mistura dos isolados CIIb e S2, qualificada como compatível, não promoveu incrementos quando comparado com a testemunha e apresentou resultado inferior em relação à aplicação dos isolados separadamente. Para biomassa radicular, a mistura M3 apresentou resultado intermediário. Os melhores tratamentos foram a microbiolização do substrato com os isolados FL2 e S2, aplicados individualmente para enraizamento e a mistura M1 (FL2 + CIIb) para biomassa
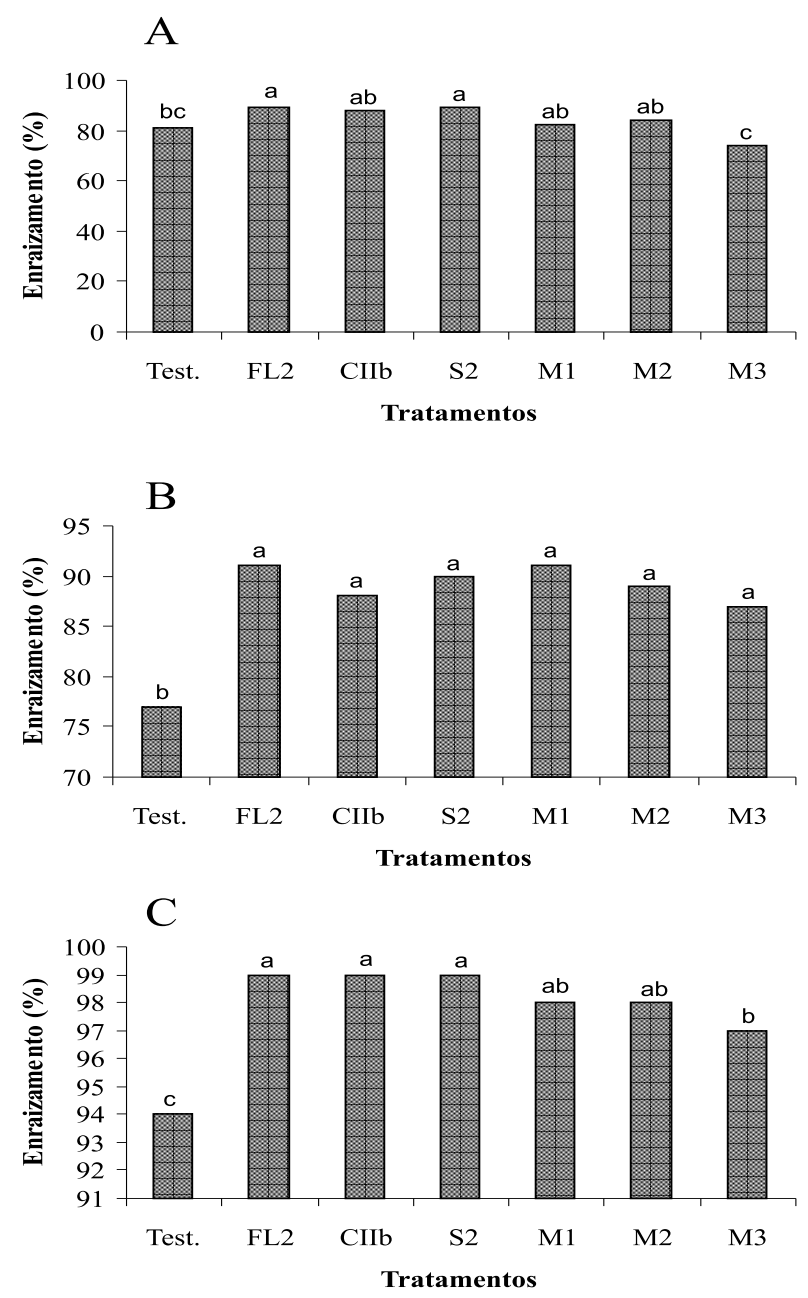

radicular, com incrementos em termos porcentuais de 10 e $239 \%$, respectivamente (Figura 3A).

No clone P4295, todos os isolados, aplicados separadamente ou em combinações, promoveram incrementos de índice de enraizamento e de biomassa radicular, com valores máximos de 18 e $88 \%$, promovido pelo isolado FL2 ou pelas misturas M1 (FL2 + CIIb) e M2 (FL2 + S2) (Figura 3B), respectivamente. Essa última combinação foi considerada incompatível nos pareamentos de culturas. A resposta foi semelhante em todos os tratamentos com isolados de rizobactérias.
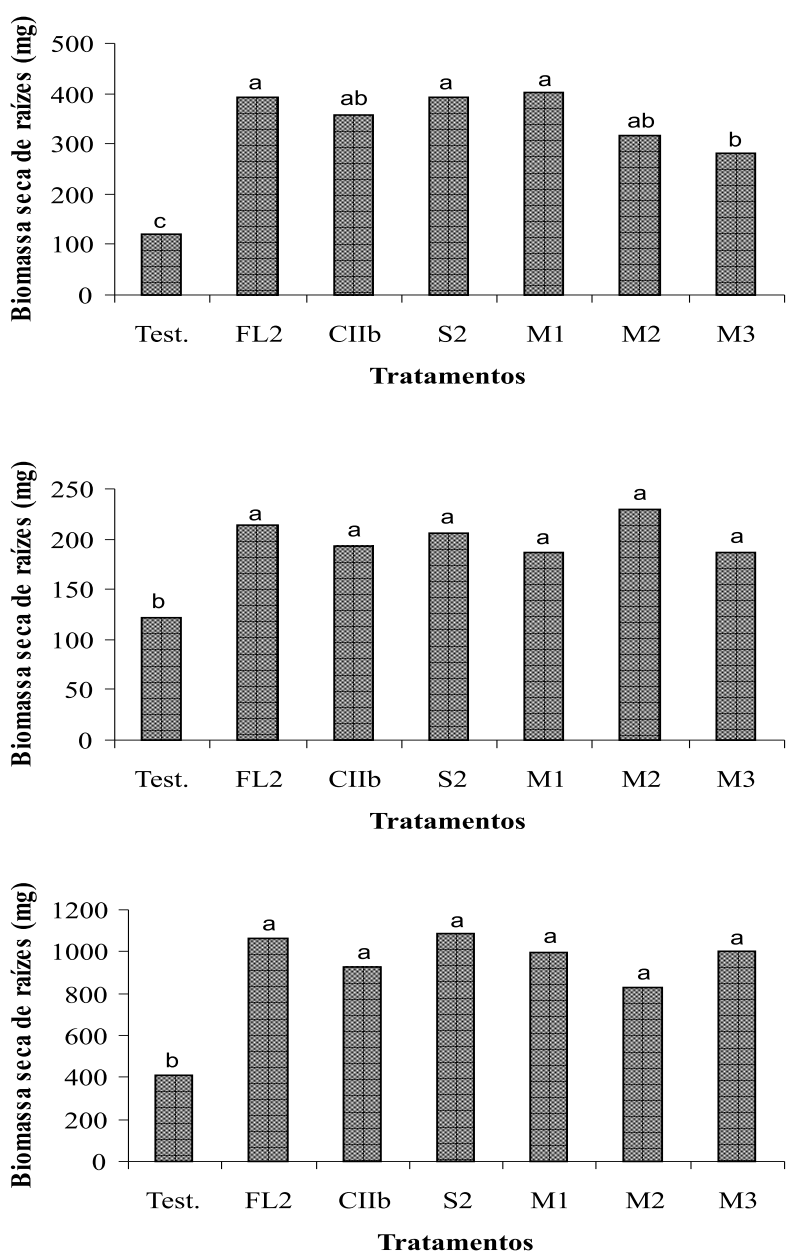

Figura 3 - Enraizamento e biomassa radicular dos clones C041 (A), P4295 (B) e VR3709 (C) propagados em substrato microbiolizado com os isolados FL2, CIIb e S2 e com as misturas M1 (FL2 + CIIb), M2 (FL2 + S2) e M3 (CIIb $+\mathrm{S} 2)$. Colunas sob a mesma letra não diferem entre si, estatisticamente, pelo teste de Tukey $(\mathrm{P}<0,05)$.

Figure 3 - Rooting (\%) and root biomass (\%) of clones C041 (A), P4295 (B) and VR3709 (B) propagated in substrate that was microbiolized with isolates $F L 2, C I I b, S 2$, or the mixtures $M 1(F L 2+C I I b), M 2(F L 2+S 2)$ or M3 $(C I I b+S 2)$. Bars with the same letters are not statistically different according to Tukey's Test $(P=0,05)$. 
No clone VR3709, a mistura M3 (CIIb + S2) apresentou resultado inferior à aplicação dos isolados separadamente para enraizamento, mesmo sendo essa mistura considerada compatível. Todavia, nessa mistura obteve-se incremento em relação à testemunha. No caso de biomassa radicular, todos os tratamentos diferiram da testemunha (Figura 3C), com incremento máximo de $162 \%$, em termos porcentuais, no tratamento com o isolado $\mathrm{S} 2$.

\section{DISCUSSÃO}

Neste trabalho, demonstrou-se o efeito benéfico da aplicação de isolados de rizobactérias sobre o enraizamento e crescimento de clones de eucalipto, conforme foi realizado previamente por Teixeira (2001) e Mafia et al. (2005). De forma similar, Gagné et al. (1993) demonstraram que a aplicação de rizobactérias $\left(10^{8}\right.$ u.f.c./mL) em substrato à base de turfa $(75 \mathrm{~mL}$ de inóculo/ $\mathrm{L}$ de substrato) aumentou a produção de tomates. $\mathrm{O}$ monitoramento da população de dois isolados mutantes, com resistência a antibióticos, evidenciou a manutenção da viabilidade das células bacterianas e a colonização do sistema radicular, sob condições normais de produção. Para eucalipto, como a produção de mudas é realizada sob condições controladas de ambiente e o substrato de produção de mudas é, geralmente, de composição orgânica, acredita-se que as possibilidades de sucesso da microbiolização do substrato com rizobactérias benéficas ainda sejam maiores.

Considerando as misturas de isolados, com vistas ao incremento no efeito benéfico sobre o enraizamento e crescimento, os resultados obtidos nos pareamentos de culturas não correlacionaram totalmente com os resultados obtidos in vivo. Desse modo, aparentemente não ocorreu sinergia entre isolados compatíveis, assim como também não ocorreu redução na eficiência da mistura de isolados incompatíveis, o que provavelmente pode estar relacionado ao mesmo modo de ação dos isolados empregados nas misturas (RAUPACH e KLOEPPER, 1998). Além disso, como não ocorreu redução na eficiência dos isolados considerados incompatíveis, é possível que, após a aplicação, o isolado que apresenta maior capacidade competitiva se estabeleça na rizosfera, em detrimento do outro utilizado na mistura.

É importante ressaltar que o pareamento de culturas foi realizado nos meios de cultura de Kado \& Heskett e B de King, com vistas a contornar um dos problemas apontados por Kloepper (1991). Segundo esse autor, a utilização do meio de Kado \& Heskett permite identificar inibição de isolados produtores de antibióticos, enquanto o meio B de King possibilita constatar inibição de um isolado por outro capaz de produzir sideróforos.

Em outro estudo, o efeito sinérgico foi comprovado por meio da aplicação de uma mistura de três isolados de rizobactérias, identificados como Bacillus pumilis Meyer \& Gottheil (INR 7), B. subtilis (GB 03) e Curtobacterium flaccumfaciens (Hodges) Collins \& Jones (ME 1). Por meio da microbiolização de sementes de pepino, constataram-se maior promoção de crescimento e redução de doenças na mistura de isolados, em comparação com o efeito dos isolados aplicados individualmente, provavelmente em virtude da conciliação de diferentes mecanismos de ação de cada um dos isolados (RAUPACH e KLOEPPER, 1998). Nesse mesmo sentido, no patossistema $R$. solani - arroz o uso de isolados de Streptomyces spp. e B. cereus Frankland $\&$ Frankland, sabidamente produtores de quitinase, em combinação com isolados de $P$. fluorescens Migula e Burkholderia cepacia Palleroni \& Holmes, produtores de antibióticos, resultou em maior supressão do patógeno (SUNG e CHUNG, 1997). No entanto, é importante considerar que, em certas situações, a mistura de diferentes isolados pode não resultar em efeito sinérgico. Além do mais, esse efeito pode não ocorrer com a mudança das condições ambientes e, ou, com a troca do material vegetal de interesse (SCHISHER et al., 1997).

Nas misturas, geralmente se adota a mesma proporção de inóculo dos isolados (RAUPACH e KLOEPPER, 1998; BOER et al., 1999), como realizado neste estudo. No entanto, outras proporções podem também surtir resultados satisfatórios. A título de exemplo, a aplicação de uma mistura de dois isolados quitinolíticos (Paenibacillus sp. 300 e Streptomyces sp. 385), na proporção $1: 1$ ou $1: 4$, foi mais efetiva no controle da murcha de Fusarium do pepino, causada por Fusarium oxysporum f. sp. cucumerinum Owen, do que quando os isolados foram aplicados individualmente (SINGH et al., 1999). É importante considerar o maior custo de produção de inoculantes compostos de misturas de isolados (RAMAMOORTHY et al., 2001). Desse modo, para minimizar os custos de produção do inoculante, pode-se optar pela realização da mistura no ato da microbiolização do substrato, conforme foi realizado, com sucesso, neste trabalho. 
Em geral, não se constatou sinergia na mistura de isolados compatíveis em relação à indução do enraizamento e crescimento. Todavia, conforme salientado por Mafia et al. (2005), a mistura de isolados pode ser interessante quando se objetiva o controle biológico de doenças do eucalipto, uma vez que nem sempre os melhores isolados promotores de crescimento são eficientes quanto à supressão de patógenos.

\section{CONCLUSÕES}

Os resultados deste trabalho permitiram concluir que a compatibilidade entre isolados de rizobactérias, avaliada pelo pareamento de culturas, não correlacionou com os resultados in vivo. Além disso, não houve sinergia da mistura de isolados compatíveis para indução do enraizamento e crescimento de clones de eucalipto expresso pela biomassa radicular, assim como também não ocorreu redução na eficiência da mistura de isolados incompatíveis.

\section{AGRADECIMENTOS}

Às empresas florestais Aracruz Celulose S.A., CAF Santa Bárbara Ltda., Cenibra S.A., Cia. Suzano Bahia-Sul dePapele Celulose, Jari Celulose S.A., Klabin Papele Celulose S.A., Lwarcel Papel e Celulose, Plantar S.A., Veracel Celulose S.A. e Votoratin Celulose e Papel (VCP), pelo apoio logístico e pelo financiamento de parte deste trabalho.

\section{REFERÊNCIAS}

AlfEnAS, A. C. et al. Clonagem e doenças do eucalipto. Viçosa, MG: Universidade Federal de Viçosa, Imprensa Universitária, 2004. 442p.

BARTLETT, M. S. The use of transformations. Biometrics, v.3, p.39-53, 1947.

BOER, M. et al. Combining fluorescent

Pseudomonas spp. strains to enhance suppression of fusarium wilt of radish. European Journal of Plant Pathology, v.105, p.201-210, 1999.

BUDGE, S. P. et al. Use of Coniothyrium minitans and Gliocladium virens for biological control of Scherotinia sclerotiorum in glasshouse lettuce. Biological Control, v.5, p.513-522, 1995.

BURR, T. J.; SCHROTH, M. N.; SUSLOW, T. Increased potato yields by treatment of seedpieces with specific strains of Pseudomonas fluorescens and P. putida. Phytopathology, v.68, p.1377-1383, 1978.
CATTELAN, A. J.; HARTEL, P. G.; FUHRMANN, J. J. Screening for plant growth-promoting rhizobacteria to promote early soybean growth. Soil Science Society of America Journal, v.63, p.1670-1680, 1999.

CHANWAY, C. P.; HOLL, F. B. First year field performance of spruce seedlings inoculated with plant growth promoting rhizobacteria.

Canadian Journal of Microbiology, v.39, p.1084-1088, 1993a.

CHANWAY, C. P.; HOLL, F. B. Ecotypic specificity of spruce emergence-stimulating Pseudomonas putida. Forest Science, v.39, p.520-527, 1993 b.

CHANWAY, C. P.; HOLL, F. B. Growth of outplanted lodgepole pine seedlings one year after inoculation with growth promoting rhizobacteria. Forest Science, v.40, p.238-246, 1994.

CHANWAY, C. P. Inoculation of tree roots with PGPR soil bacteria: an emerging technology for reforestation. Forest Science, v.43, p.99-112, 1997.

DATNOFF, L. W.; NEMEC, S.; POHRONEZNY, K. Influence of Trichoderma harzianum and Glomus intraradices on incidence and severity of Fusarium crown and root rot. Biological Cultural Test, v.9, p.78, 1993.

DATNOFF, L. E.; NEMEC, S.; PERNEZNY, K. Biological control of Fusarium crown and root rot of tomato in Florida using Trichoderma harzianum and Glomus intraradices.

Biological Control, v.5, p.427-431, 1995.

DUFFY, B. K.; WELLER, D. M. Use of Gaeumannomyces graminis var. graminis alone and in combination with fluorescent Pseudomonas spp. to suppress take-all of wheat. Plant Disease, v.79, p.907-911, 1995.

DUFFY, B. K.; WIMON, A.; WELLER, D. M. Combination of Thichoderma koningii with fluorescent pseudomonads for control of take-all on wheat. Phytopathology, v.86, p.188-194, 1996.

ENEBACK, S. A.; WEI, G.; KLOEPPER, J. W. Effects of PGPR on loblolly and slash pine seedlings. Forest Science, v.44, p.139-144, 1998.

R. Árvore, Viçosa-MG, v.31, n.4, p.635-643, 2007 
EUCLYDES, R. F. Manual de utilização do programa SAEG (Sistema para

Análises Estatística e Genética). Viçosa, MG: Universidade Federal de Viçosa, 1983.

GAGNÉ, S. et al. Increase of greenhouse tomato fruit yields by plant growth-promoting rhizobacteria (PGPR) inoculated into the peatbased growing media. Soil Biology and Biochemistry, v.25, p.269-272, 1993.

ISWANDI, A. et al. Effect of the seed inoculation with the rhizopseudomonad strains 7 NSK 2 on the root microbiota of maize (Zea mays) and barley (Hordeum vulgare). Biology and Fertility of Soils, v.3, p.153-158, 1987.

JANISIEWICZ, W. J. Ecological diversity, niche overlap, and coexistence of antagonists used in developing mixtures for biocontrol of post-harvest diseases of apples. Phytopathology, v.86, p.473-479, 1996.

JOHNSON, K. B. et al. Effect of antagonistic bacteria on establishment of honey bee-dispersed Erwinia amylovora in pear blossoms and on fire blight control. Phytopathology, v.83, p.995-1002, 1993.

KADO, E. I.; HESKETT, M. G. Selective media for isolation of Agrobacterium, Corynebacterium, Erwinia, Pseudomonas and Xanthomonas.

Phytopathology, v.60, p.969-976, 1970.

KING, E. O.; WARD, M. K.; RANEY, D. E. Two simple media for the demonstration of pyocyanin and fluorescin. Journal of Laboratory and Clinical Medicine, v.44, p.301-307, 1954.

KLOEPPER, J. W.; SCHROTH, M. M. Plant growth promoting rhizobacteria on radishes. In: INTERNATIONAL CONFERENCE ON PLANT PATHOGENIC BACTERIA, 4, 1978, Angers. Proceedings... Angers: 1978. p.879-882.

KLOEPPER, J. W. Development of in vivo assays for prescreening antagonists of Rhizoctonia solani on cotton Phytopathology, v.81, p.1006-1013, 1991.

KLOEPPER, J. W.; SCHROTH, M. N.; MILLER, T. D. Effects of rhizosphere colonization by plant growth-promoting rhizobacteria on potato plant development and yield. Phytopathology, v.70, p.1078-1082, 1980.

R. Árvore, Viçosa-MG, v.31, n.4, p.635-643, 2007
KLOEPPER, J. W. et al. Plant growth-promoting rhizobacteria on canola (rape-seed). Plant Disease, v.72, p.42-46, 1988.

LALANDE, R. et al. Identification of rhizobacteria from maize and determination of their plantgrowth promoting potential. Plant and Soil, v.115, p.7-11, 1989.

LEEMAN, M. et al. Suppression of fusarium wilt of radish by co-inoculation of fluorescent Pseudomonas spp. and root-colonizing fungi. European Journal of Plant Pathology, v.102, p.21-31, 1996.

MAFIA, R. G. et al. Crescimento de mudas e produtividade de minijardins clonais de eucalipto tratados com rizobactérias selecionadas. Revista Árvore, v.29, p.843-851, 2005.

PIERSON, E. A.; WELLER, D. M. Use of mixtures of fluorescent pseudomonads to suppress take-all and improve growth of wheat.

Phytopathology, v.84, p.940-947, 1994.

POLONENKO, D. R. et al. Effects of root colonizing bacteria on nodulation of soybeans roots by Bradyrhizobium japonicum. Canadian Journal of Microbiology, v.33, p.498-503, 1987.

RAAIJMAKERS, J. M. et al. Utilization of heterologous siderophores and rhizosphere competence of fluorescent Pseudomonas spp. Canadian Journal of Microbiology, v.41, p.126-135, 1995.

RAMAMOORTHY, V. et al. Induction of systemic resistance by plant growth promoting rhizobacteria in crop plants against pests and diseases. Crop Protection, v.20, p.1-11, 2001.

RAUPACH, G. S.; KLOEPPER, J. W. Mixtures of plant growth-promoting rhizobacteria enhance biological control of multiple cucumber pathogens. Phytopathology, v.88, p.1158-1164, 1998.

SCHISLER, D. A.; SLININGER, P. J.; BOTHAST, R. J. Effects of antagonist cell concentration and two-strain mixtures on biological control of Fusarium dry rot of potatoes. Phytopathology, v.87, p.177-183, 1997. 
SHISHIDO, M.; CHANWAY, C. P. Colonization and growth promotion of outplanted spruce seedlings pré-inoculated with plant growthpromoting rhizobacteria in the greenhouse.

Canadian Journal of Forest Research, v.30, p.845-854, 2000.

SINGH, P. P. et al. Biological control of Fusarium wilt of cucumber by chitinolytic bacteria.

Phytopathology, v.89, p.92-99, 1999.

STOCKWELL, V. O.; JOHNSON, K .B.; LOPER, J. E. Compatibility of bacterial antagonists of Erwinia amylovora wit antibiotics used to control fire bright. Phytopathology, v.86, p.834-840, 1996.

SUNG, K. C.; CHUNG, Y. R. Enhanced suppression of rice sheath blight using combination of bacteria which produce chitinases or antibiotics. In: Plant growth-promoting rhizobacteria - Present status and future prospects. INTERNATIONAL WORKSHOP ON PLANT GROWTH PROMOTING RHIZOBACTERIA, 4, 1997, Sapporo

Proceedings... Sapporo: 1997. p.370-372.
SUSLOW, T. V.; SCHROTH, M. N. Rhizobacteria of sugarbeet: effects of seed application and root colonization on yield. Phytopathology, v.72, p.199-206, 1982.

TEIXeira, D. A. Promoção de enraizamento e indução de resistência sistêmica à ferrugem e à mancha-de-Cylindrocladium, mediadas por rizobactérias em clones de Eucalyptus spp. 2001. 67f. Tese

(Doutorado em Fitopatologia) - Universidade Federal de Viçosa, Viçosa, MG: 2001.

TURNER, J. T.; BACKMAN, P. A. Factors relating to peanut yield increases after seed treatment with Bacillus subtilis. Plant Disease, v.75, p.347-353, 1991.

WELLER, D. M.; COOK, R. J. Increased growth of wheat by seed treatments with fluorescent pseudomanads, and implications of Pythium control. Canadian Journal of Plant Pathology, v.8, p.328-334,1986. 
